\title{
Empirical Research on Scientific and Technical Innovation and Economic Growth in Shanghai
}

\author{
Lei Weng, Wei Song, Si-Bei Sheng \\ University of Science and Technology of China, Hefei, China \\ Email: weng2009@mail.ustc.edu.cn \\ Received October 25, 2011; revised December 20, 2011; accepted January 10, 2012
}

\begin{abstract}
With the explosive growth of knowledge and the further improvement of economic globalization, technology gradually represents its greater significance as the core factor of the strategic resources and competence for national and regional development, which becomes a greater support to the construction of the innovative country and also a key to take the initiative to develop. Under this tendency, technological improvements should play a more important role in pushing the economy forwards, which brings higher requirements for technical development in Shanghai. Thus Shanghai must integrate and utilize the resources of new technology in a more comprehensive way. During the process of building up a well-off society as well as innovative regions in an all-around way, the demand for technological innovation is continuously increasing and its content, as to Shanghai, is undergoing further fulfillment. The study on the inner connection between Shanghai technological development and economic growth, thus under such background, means much to get a knowledge about the dynamic equilibrium relationship between technical progress and economic growth, which can be taken as an important reference for the government to draw up the plan for future technological development.
\end{abstract}

Keywords: Technology Innovation Output; Economic Growth; Patents; VAR Model; Shanghai

\section{Introduction}

The forerunner of Economics, Adam Smith and David Richardo developed the Classical Economics. They recognize that land, capital and labor were the factors that improved the economy. The Neo-classic growth theory represented by Robert Solow, Swan, Koopmans, negated the non-changeable factors of the classic economic growth theory, and in their view, it pointed out the diminishing capital return theory and brought in the exogenous variable knowledge and technology which admitted the effect the technological advance might have on economic growth but only on the sense that the technology improvements were only the exogenous variables in the economic growth. The New Growth Theory represented by Romer, Robert Lucas, Gary Beeker and Yang Xiaokai, believe that the advance in science and technology is the most significant motive to enhance the economic growth and social development [1-3].

In the study of development economics, people recognized the great role that technology spillover plays to improve the economy in the developing countries. Caves studied the effects of FDI technology spillover in Canada and Australia, which dug out that the spillover brought out by the foreign investment of both countries balanced their economic development in the long term [4]. Blom- storm found that the manufacturing capability of these enterprises in these industries were compatible with that of companies with foreign investments [5]. Along with the development and change with the times, the influence of technology advance on economic growth is becoming more obvious and the study on the relation of these two is deepening. Geoffrey G. Gachino has established a unique analytical framework from three aspects including cluster and network dynamics, technological innovations and spillover literature, to research the technology spillover in the industry of manufacturing, and he indicates that the degree of technology spillover is related to the policies and regional background of technology transfer countries [6] Blomström M. and Kokko A. study on the optimization of technology transfer licensing, which is the main approach for technology spillover, the technology spillover from the technology export country to the technology transfer country can be achieved by means of investment abroad, and the policies of technology licensing in the technology export countries impose a direct impact on the effect of technology spillover [7]. LESER CEV studies the measurement for the impact of technological advance on the economic growth in Germany, and the result of research shows that there is a long-term equilibrium relationship between technological advance and economic growth, and the impact of tech- 
nological advance on the economic growth will be increasingly greater over time, and advance in technology will turn out to be the most important influencing factor of economic growth in the future [8]. Kanygin I. M. profoundly analyzes the relationship between science \& technology and economic growth, and the result of study shows that science \& technology is an important factor which can influence the economic growth in modern times [9]. The advance of science and technology improves the quality of labor and efficiency of capital in an indirect way, thus the development of science and technology is the basic motive for economic growth in the long run. Baiqing Ye and Xiaomei Sun probe into the functional mechanism between technological innovation and economy, to set up the indicator system of technological innovation. An in-depth classification study on the data from different countries has been carried out based on technological innovation, and moreover, the relationship between technological innovation and economic growth has been analyzed [10]. Greiner A and Rubart J and Semmler W carry out the research about the impact of scientific and technological progress on the wage inequality, and empirically analyzes that the advance of science and technology is an important explanatory variable for wage inequality. The advance of science and technology widens the gap of educational level among laborers, which can indirectly influence the efficiency of labor, thus the difference in the efficiency of labor is the immediate cause for wage inequality, in that the advance of science and technology is an indirect factor for wage inequality [11]. When the fact that technological innovation plays a promoting role in the growth of economy has been widely recognized, Johnson Bjorn is devoted to the study about the impact of institu- tional innovation and political innovation on the technical innovation and economic growth [12]. According to his research, it can be seen that the power of technical innovation is to be challenged when promoting the development and growth of economy in the urban area, especially in these developed cities, while institutional innovation and political innovation are of particular importance compared with technical innovation. There is a close relationship between the advance of science and technology and economic growth. The production in the economic sector requires the indispensable research and development, to popularize the new technique in the market. Czech Brian notes that the current progress in technology is economy-oriented, with the goal of economic growth, thus the probability of technological development with the help of other approaches is smaller [13].

The above-mentioned studies investigate the relationship between the advance of science \& technology and economic growth from different points of view in different ways, and the conclusions are various. However, of all the above studies, there is no study on the promotion effect of science and technology progress on the economic growth from the perspective of science and technology output, and also there are few researches on the interactive relation between science and technology advance and the economic growth, furthermore, the quantitative association between variables has not been studied yet.

Based on previous studies, this paper construct interpretation model of technological progress and economic growth as Figure 1.

In the model, it can be seen that labor, capital and technology can promote the development of economy,

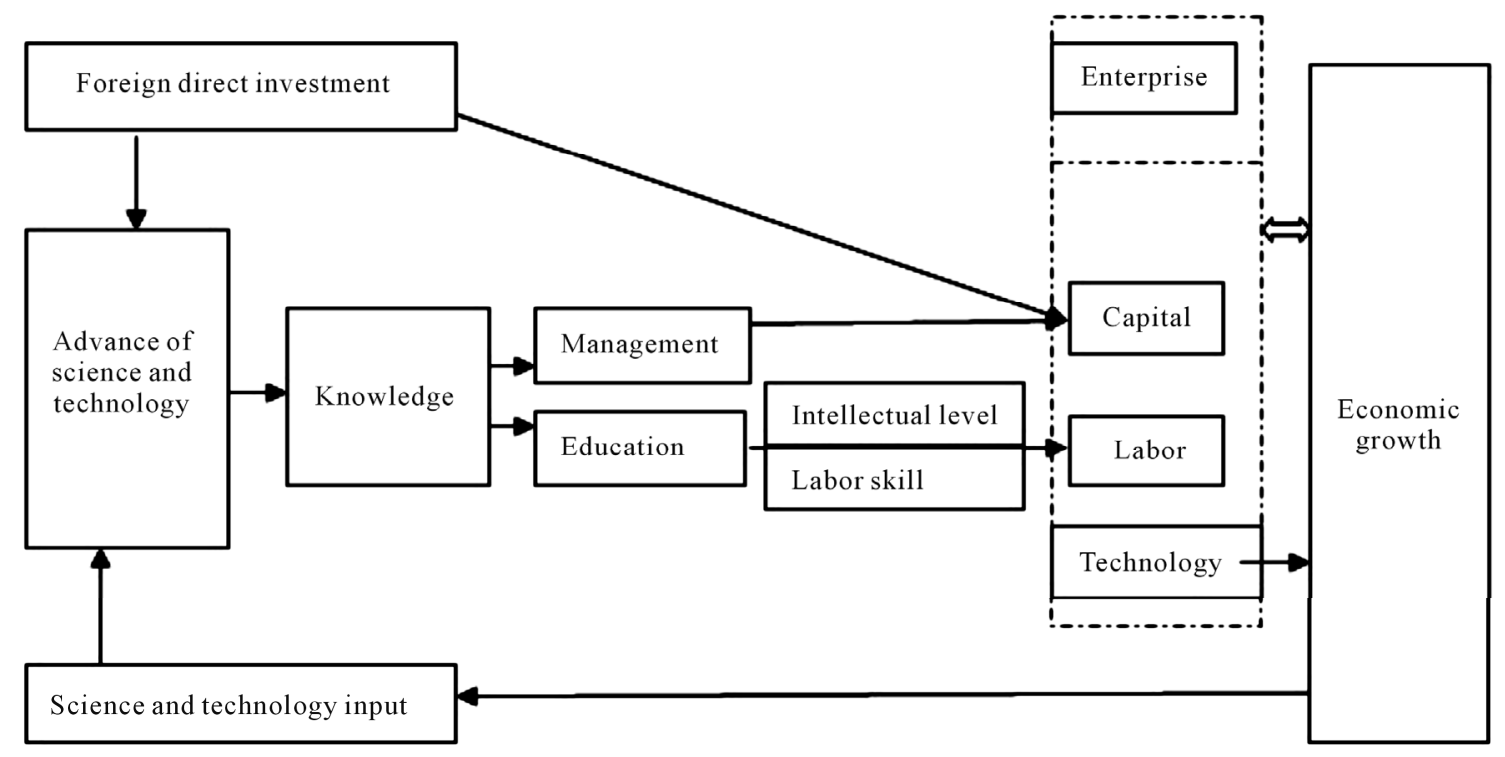

Figure 1. Interpretation model of science \& technology and economic growth. 
while the economic growth can influence labor, capital and technology as well, that is to say, the effect is bidirectional and mutual, the output of science and technology push the economic development forward, at the meantime, it also affects labor and capital; knowledge pertains to the science and technology output, which can increase the combination efficiency of labor and capital by means of education and management, to promote the growth in economy; foreign direct investment has not only brought the capital, what's more, it comes with technology, and the technology spillover is directly represented in the advance of science and technology in the regions where technology is spilled, and it effectively facilitates the development of local social economy.

Based on the previous research results, this paper represents the empirical research on the related indexes of science and technology output and economic growth by using the relevant data from 1991 to 2009 with the help of vector auto-regression model, and VAR model has been set up by means of testing the interactive relation among variables, at the meanwhile, it also quantitatively analyzes the influence of variables by using a few methods such as impulse response function and variance decomposition.

\section{Science and Technology Output in Shanghai}

Quantity of Shanghai patent applications as Figure 2.

The quality of patent applications in Shanghai increases rapidly, especially during the period of "Eleventh Five-Year Plan", it shows an explosive growth perpendicularly, and in the year of 2010, the number of patent applications which has been issued in Shanghai reaches up to 71,200 , an increase of $14.4 \%$ over the previous year, and the patent quality has been improved with each passing day, there are 26,200 patents of invention and 735 PCT international patent applications, which increases by $49.1 \%$, in the year of 2010 , the amount of inventive patents per a million people in Shanghai goes up to 299, achieving the standard level of moderately developed countries. For the trademark application, 60,243 trademarks have been applied for registration in Shanghai during the year of 2010, an increase of $43.8 \%$, and there are 70,417 trademarks with approval of Registration, increasing by 95.7, 256 trademarks are newly recognized as the famous trademarks in Shanghai. The development of literary property is also remarkable, and 7905 cases for software copyright have been registered in 2010, an increase of $44.38 \%$; there are 2636 cases for other kinds of copyright, showing an increase of $18.89 \%$, and moreover, 281 layout designs of integrated circuits have been registered, which accounts for $25.6 \%$ of the total amount in the whole country. Great progress has

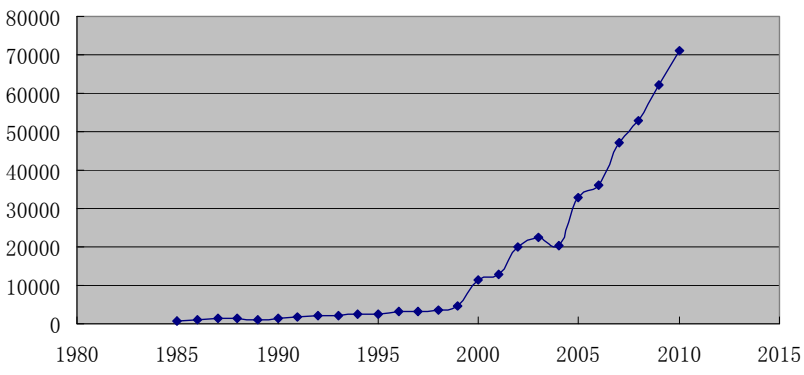

Figure 2. Statistical graph of the quality of patent applications in Shanghai ${ }^{1}$.

been made in terms of scientific and technological achievements in Shanghai, 2318 cases of scientific and technological achievements has been achieved in Shanghai during the year of 2010, of all the award winners and projects which have already been issued in the 2010 State Science and Technology Prizes, 58 projects (winners) are from Shanghai, which makes up $16.35 \%$ of the total. This information fully indicates the relatively high level of innovation, management, protection and application capability of Shanghai in the field of intellectual property such as patent and copyright.

\section{VAR Model and Data Processing}

VAR model (Vector Autoregressive Model) was put forward by Sims in 1980 [14], and this model does not need to be in the strict accordance with any economic theory, endogenous variables regress all the lagged values of them in each equation of this model, thus the dynamic relationship among all the endogenous variables can be estimated. VAR model has many merits, for instance, it does not require any strict economic theory as its basis, it does not impose any restraints on the parameters, and no current variable is included in the explanatory variables, for all of these reasons, this kind of model is welcomed by the scholars who study the dynamic time series data.

In this paper, VAR model has been established as follows:

$$
\begin{aligned}
& \text { LnPGDP }=\sum \text { LnPGDP }_{t}+\sum \text { LnPa }_{\mathrm{t}}+\sum \text { LnPJSJY }_{\mathrm{t}} \\
& +\sum \operatorname{LnPFDI}_{\mathrm{t}}+\mathrm{u} \\
& \operatorname{LnPa}=\sum \operatorname{LnPGDP}_{\mathrm{t}}+\sum \mathrm{LnPa}_{\mathrm{t}}+\sum \text { LnPJSJY }_{\mathrm{t}} \\
& +\sum \operatorname{LnPFDI}_{\mathrm{t}}+\mathrm{u} \\
& \text { LnPJSJY }=\sum \text { LnPGDP }_{t}+\sum \text { LnPa }_{t}+\sum \text { LnPJSJY }_{t} \\
& +\sum \operatorname{LnPFDI}_{\mathrm{t}}+\mathrm{u} \\
& \text { LnPFDI }=\sum \operatorname{LnPGDP}_{\mathrm{t}}+\sum \mathrm{LnPa}_{\mathrm{t}}+\sum \text { LnPJSJY }_{\mathrm{t}} \\
& +\sum \operatorname{LnPFDI}_{\mathrm{t}}+\mathrm{u}
\end{aligned}
$$

\footnotetext{
${ }^{1}$ http://www.sipa.gov.cn/
} 
LnPGDP: the economic growth index, indicating the growth in economy;

LnPa: the quantum index of patent application, representing the quantity of patent application;

LnPJSJY: the trading volume index in the market of technologies, standing for the sum of business transacttions in the market of technologies;

LnPFDI: the foreign direct investment index, LnPa, LnPJSJY and LnPFDI refer to the indicators of science and technology output.

$\mathrm{t}=1,2, \cdots ; \mathrm{u}$ is the stochastic error, which is called as pulse value in VAR terms.

This paper takes the gross domestic product (GDP) in Shanghai as the measurement index for the economic growth, and the quantity of patent application, the trading volume in the market of technologies and foreign direct investment are regarded as the indicators for science and technology output, and the value of $\mathrm{P}$ is the price index in the current year which is calculated based on the fixed price in 1978. Patentee knows well about this technology when applying for a patent, the procedure of patent licensing requires a long time for review and approval, thus it will become more persuasive with timeliness when taking the quantity of patent application as the measurement index for science and technology output, rather than the quantity of patent licensing. The data comes from the statistical yearbook in Shanghai, and this paper collects the relevant data from 1991 to 2009 and revises the price indexes in the initial data, at the meanwhile, the data in the year of 1991 is selected as the standard for data normalization, and then, four groups of data including LnPGDP, LnPa, LnPJSJY and LnPFDI can be obtained by processing these standardized data with the method of logarithm.

\section{Empirical Analysis}

\subsection{Stationary Test}

Because the economic growth index, the quantum index of patent application, the trading volume index in the market of technologies and the foreign direct investment index are all time series data, which will significantly change with time, it is necessary to test whether the variable is stationary before establishing the model. This paper carries out the stationary test for LnPGDP, LnPa, LnPJSJY and LnPFDI in the Table $\mathbf{1}$ as well as their first-order differential variables DLnPGDP, DLnPa, DLnPJSJY and DLnPFDI with the test method of ADF by Dickey_Fuller, and the result is shown in Table 1.

From the chart above, it can be known that when the level of significance is under $10 \%$, although the time series variables LnPGDP, LnPa, LnPJSJY and LnPFDI are non-stationary, their differential variables DLnPGDP, DlnPa, DLnPJSJY and DLnPFDI are all stationary series.

\subsection{Co-Integration Test}

For the unit root test result of each series, LnPGDP, LnPa, LnPJSJY and LnPFDI are all first-order integrated series, and there may be a kind of co-integration relationship among these three parties. In the paper, Johansen test method has been employed to determine whether the co-integration exists or not. If there is a co-integration relationship, the vector autoregression model (VAR) should be established to reflect the short-term and longterm relationship among variables, and the lag order should be consistent with that of co-integration test. Unconstrained VAR model is built up to determine the optimal lag order of co-integration relationship among the variables, and the effect of model is the best when selecting the second-order lag based on the comprehensive comparison among the statistics including $\operatorname{LogL}, \mathrm{LR}$, FPE, SC, AIC and HQ. When Johansen co-integration test is conducted at this time, the result shows that the economic growth, patent application and transaction in the market of technologies have the sole co-integrated vector under complete sample. Co-integration test result as Table 2.

According to the result of calculation by software, the co-integration relationship among these three variables is as follows:

$$
\begin{aligned}
\text { LnPGDP }= & 0.42667 \mathrm{LnPa}+0.39731 \mathrm{LnPJSJY} \\
& +0.21169 \mathrm{LnPFDI}
\end{aligned}
$$

From the co-integration relationship, it is can be seen that there is a long-term equilibrium relationship among the economic growth index, the quantum index of patent application, the trading volume index in the market of

Table 1. Result of stationary test.

\begin{tabular}{ccccc}
\hline & ADF & $\mathbf{( c , t , k )}$ & $\mathbf{1 0 \%}$ & Conclusion \\
\hline LnPGDP & 0.586933 & $(\mathrm{c}, \mathrm{t}, 2)$ & -2.673459 & non-stationary \\
LnPa & -0.188508 & $(\mathrm{c}, \mathrm{t}, 2)$ & -2.666593 & non-stationary \\
LnPJSJY & 0.058786 & $(\mathrm{c}, \mathrm{t}, 2)$ & -2.660551 & non-stationary \\
LnPFDI & 0.097541 & $(\mathrm{c}, \mathrm{t}, 2)$ & -2.673459 & non-stationary \\
DLnPGDP & -2.696419 & $(\mathrm{c}, \mathrm{t}, 2)$ & -2.673459 & stationary \\
DInPa & -2.720331 & $(\mathrm{c}, \mathrm{t}, 2)$ & -2.673459 & stationary \\
DLnPJSJY & -4.192489 & $(\mathrm{c}, \mathrm{t}, 2)$ & -2.666593 & stationary \\
DLnPFDI & -3.578286 & $(\mathrm{c}, \mathrm{t}, 2)$ & -2.666593 & stationary \\
\hline
\end{tabular}

Table 2. Result of co-integration relationship test.

\begin{tabular}{ccccc}
\hline & Trace statistic & $\mathbf{5 \%}$ critical value & P value & Conclusion \\
\hline $\mathrm{r}=0$ & 79.73758 & 47.85613 & 0.0000 & $\begin{array}{c}\text { There is one } \\
\text { co-integration } \\
\text { relationship }\end{array}$ \\
$\mathrm{r}=1$ & 27.58773 & 29.79707 & 0.1620 & \\
\hline
\end{tabular}


technologies and the foreign direct investment index in Shanghai from 1991 to 2009, and the coefficients of quantum index of patent application, trading volume index in the market of technologies as well as the index of foreign direct investment are all positive values, thus in the long run, the growth in economy is in positive correlation with the quantity of patent application, the sum of business transaction in the market of technologies and foreign direct investment. According to the co-integration equation, the maximum value of patent application quantum index is 0.42667 , followed by the transaction in the market of technologies and foreign direct investment. The output quantity of patent can promote the economic growth more significantly in the long run, $42.7 \%$ of the patent output index has influenced the economic growth index, which shows that patent plays an important role in facilitating the development of economy.

\subsection{Regression Model and Its Test}

Eviews 6.0 software has been used for data analysis, and the established second order VAR model is shown as Table 3.

The vector auto-regression model of regional economic growth index has been selected.

From the short-term variation in the growth of economy, in addition to the influence on themselves, the influence rate of patent output and transaction in the market of technologies on the current economic growth is $12.9 \%$ and $8.9 \%$ respectively, thus the influence is not remarkable, which suggests that the growth in economy significantly relies on the long-term equilibrium relationship. From the coefficients of other equations in the above chart, it is can be found that the influence coefficient of economic growth to patent output and technology market transactions is great, indicating that the economic growth has a greater demand for science and technology.

Model Checking: AR test method is generally used for VAR model checking, in other words, all the reciprocals of root model in this model is less than 1 , the model is stationary within the unit circle, otherwise it is not stationary, and the result is invalid. The model has been tested by AR test method, and the location mapping of each characteristic root has been made (as shown in the Figure 3), all of the characteristic roots are within the scope of unit circle, suggesting that the model in this paper is stationary, and the result obtained is valid. At the mean time, the goodness of fit $\mathrm{R}^{2}$ for each obtained VAR model in this paper is more than 0.9 , which indicates that the fitting of model is excellent.

\subsection{Impulse Response Analysis}

In order to solve the interaction problem among variables
Table 3. Coefficient chart of each variable in VAR model.

\begin{tabular}{ccccc}
\hline & LnPGDP & LnPA & LnPJSJY & LnPFDI \\
\hline LnPGDP(-1) & 1.329778 & 1.727897 & -1.787437 & 0.805183 \\
LnPGDP(-2) & -0.431029 & -0.738456 & 3.172877 & -0.979380 \\
LnPA(-1) & -0.129483 & 0.565958 & -0.102926 & -0.285031 \\
LnPA(-2) & 0.006896 & -0.186997 & -0.547611 & 0.597479 \\
LnPJSJY(-1) & 0.088958 & 0.296567 & 0.520559 & 0.187542 \\
LnPJSJY(-2) & 0.072352 & -0.123719 & 0.515822 & 0.010998 \\
LnPFDI(-1) & -0.036147 & -0.173423 & -0.119973 & -0.227129 \\
LnPFDI(-2) & 0.001435 & -0.048265 & -0.110524 & -0.098726 \\
U & 0.601298 & -1.236206 & -1.822342 & 7.533605 \\
R-squared & 0.998592 & 0.989598 & 0.979863 & 0.907411 \\
Adj. R-squared & 0.997185 & 0.979195 & 0.959725 & 0.814823 \\
\hline
\end{tabular}

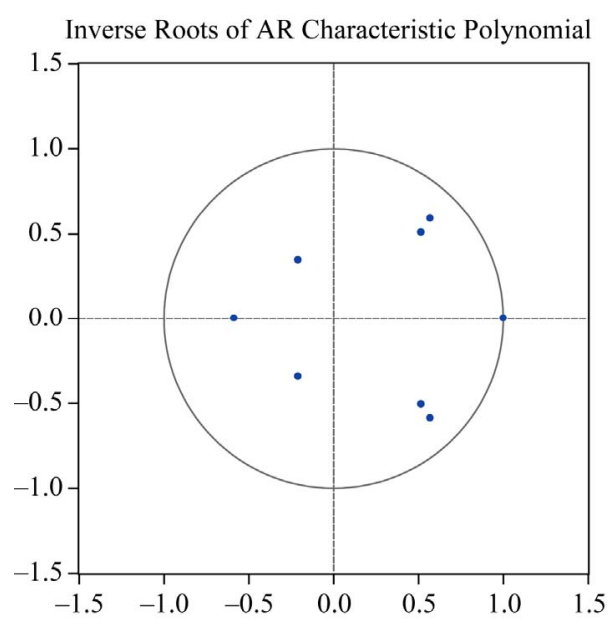

Figure 3. Model AR test chart.

in the model, the method of impulse response analysis has been used in this paper. Cholesky decomposition, in which a variable is impacted, and the impulse response functional arrangement of the altered variable to other variables can be obtained. The horizontal axis shows the number of lag period (unit: year) of the impact effect, while the vertical axis means the variation of variables, the solid line indicates the impulse response function, representing the response of variables change to the impact of relevant variables.

From Figure 4, it is can be obtained that the positive impulse of patent output on the economic growth is positive in the first four years, while the influence of transaction in the market of technologies and foreign direct investment on the economic growth is negligible. The impact of economic growth on the patent output has constantly increased during the first four years, and afterwards, it declines slightly, but still showing its positive 


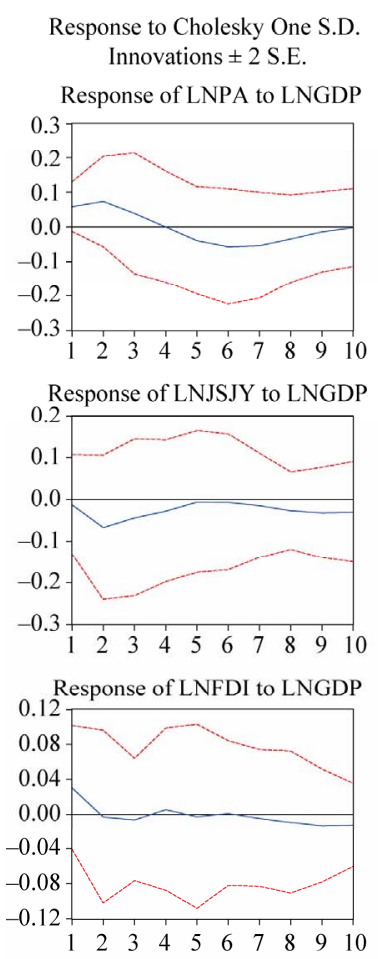

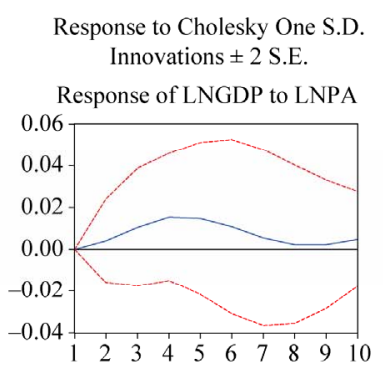
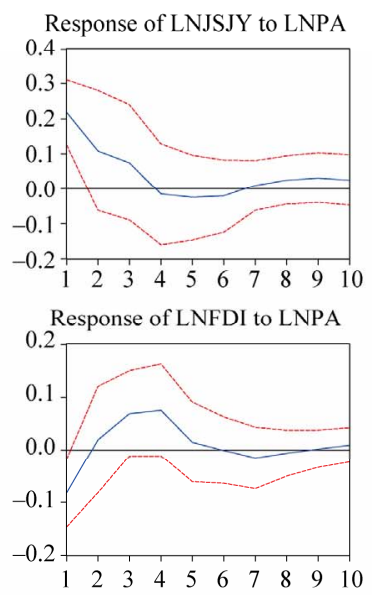

Response to Cholesky One S.D. Innovations \pm 2 S.E.
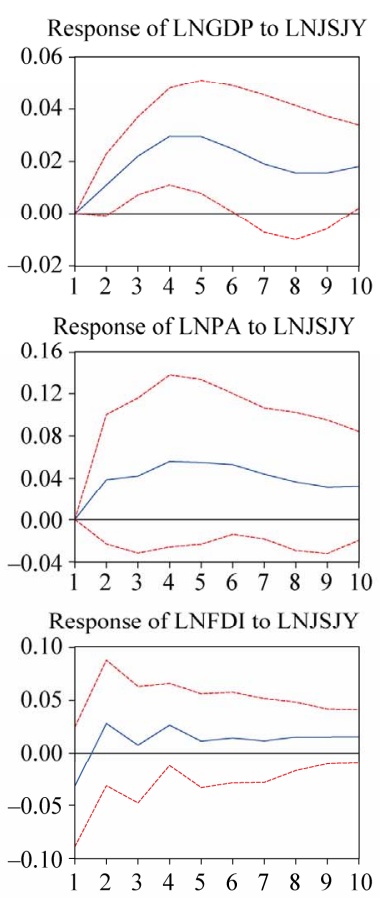

Response to Cholesky One S.D. Innovations \pm 2 S.E.
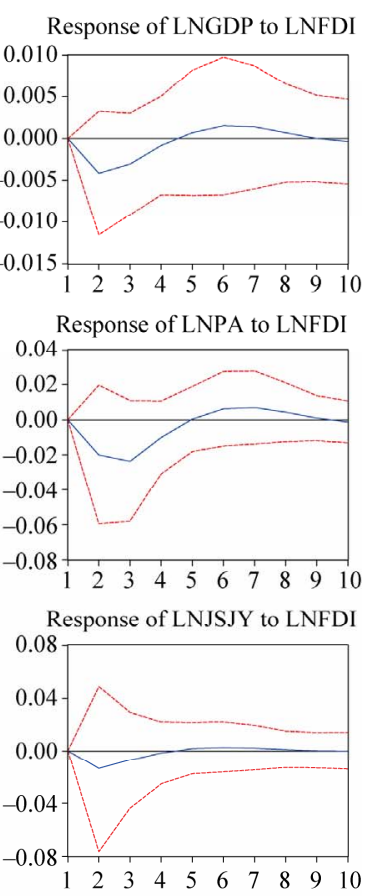

Figure 4. Impulse response analysis.

impact; the effect of economic growth on the transaction in the market of technologies is comparatively evident, the strength of impact increases in the first four years, and after that, it also continue to maintain a high level, the impact of economic growth index on the foreign investment index is not obvious. The impact of transaction in the technology market on the patent output is positive in the first four years, and it shows a tendency of decrease with each passing year; the impact of foreign direct investment is positive from the second year to the sixth year, and afterwards, it is not so remarkable. The influence of patent output on the transaction in the technology market always maintain a high level after the second year, and the impact of foreign direct investment on the transaction in the technology market is always positive. The impact of changes in patent output and transaction in technology market on the foreign direct investment is negligible.

\subsection{Variance Decomposition Analysis}

Impulse response function describes the influence of shock in an endogenous variable on the other variables in the model of VAR. However, the process of variance decomposition decomposes the changes in the endogenous variable into the component impact to the VAR model. Thus, the variance decomposition provides some relatively important information for each stochastic disturbance which causes the impact on the variables in
VAR.

From Figure 5, it can be seen that transaction in technology market has a significant impact on the short-term variation in economic growth, reaching up to $40 \%$ - 50\%, and the contribution rate of short-term patent output to the variation in economic growth is going up constantly during the first four periods, and after that, the influence rate is stable at $10 \%$, and the impact of foreign investment to the variation in economic growth is not notable in the short run. The impact of economic growth on the variation in patent output shows a positive correlation, the contribution rate of influence is around $20 \%$, and in addition, the impact of transaction in the technology market on the patent output increases with time, and it is stable at $20 \%$ after the fifth period, the influence of foreign direct investment on the changes in economic growth is non-significant. The influence rate of economic growth on the volume of business transactions in technology market maintains a level of $10 \%$ approximately, and the influence rate of patent output on the transaction in technology market is the most significant, which is up to $60 \%-80 \%$, the impact of foreign direct investment on the transaction in technology market is not remarkable; the effect of economic on the foreign direct investment is slight, accounting for $5 \%$ of the positive influence, while the impact of patent output on the variation in foreign direct investment is more significant, and its influence rate stabilizes at around $50 \%$ in the fourth period, the transaction in technology market shows a $10 \%$ positive 
Variance Decomposition

Percent LNGDP variance due to LNGDP Percent LNGDP variance due to LNPA
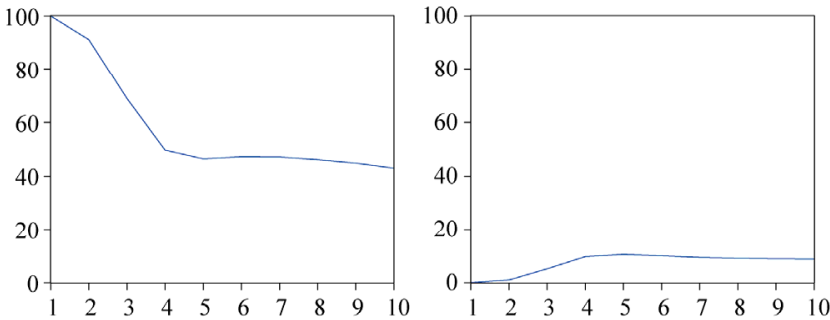

Percent LNGDP variance due to LNJSJY Percent LNGDP variance due to LNFDI
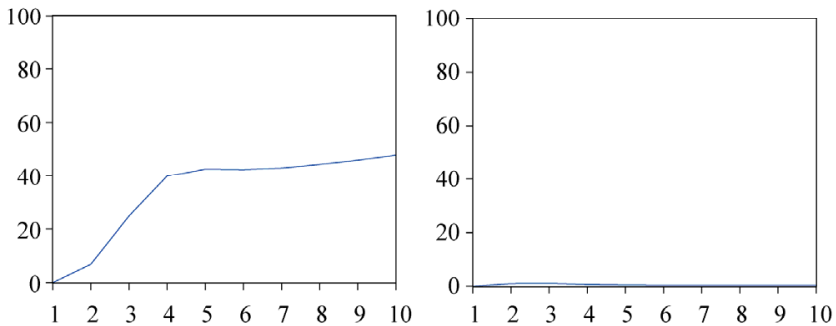

Variance Decomposition

Percent LNPA variance due to LNGDP Percent LNPA variance due to LNPA
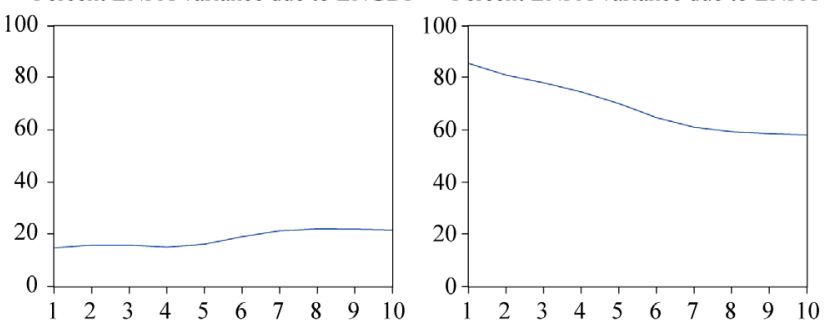

Percent LNPA variance due to LNJSJY
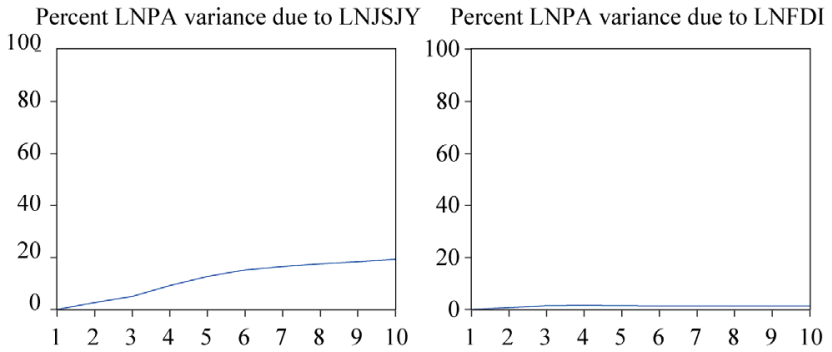

Figure 5. Variance decomposition analysis.

Variance Decomposition

Percent LNJSJY variance due to LNGDP Percent LNJSJY variance due to LNPA
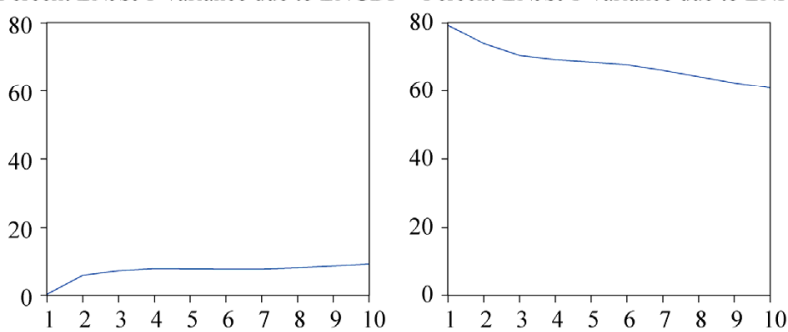

Percent LNJSJY variance due to LNJSJY Percent LNJSJY variance due to LNFDI
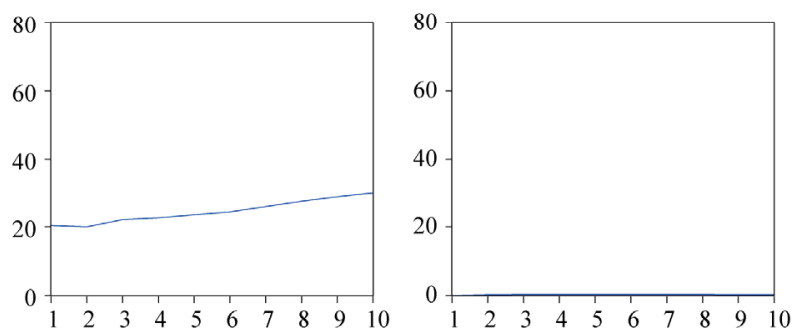

Variance Decomposition

Percent LNFDI variance due to LNGDP Percent LNFDI variance due to LNPA
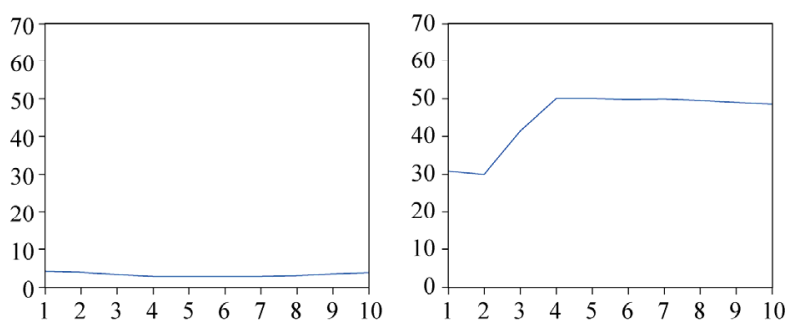

Percent LNFDI variance due to LNJSJY
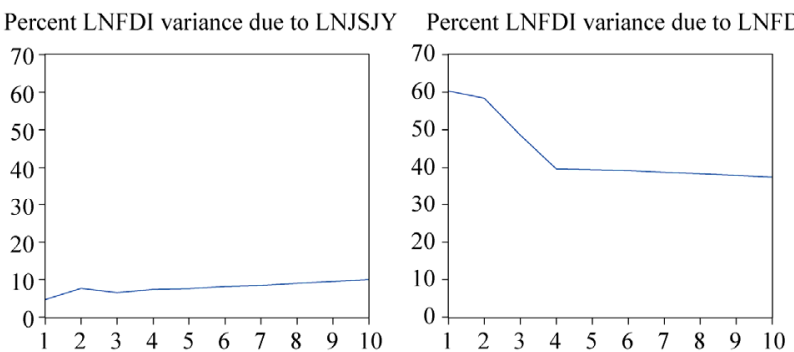

impact on the foreign direct investment.

\section{Conclusions}

From the co-integration relationship, it can be concluded that there is a long-term equilibrium relationship among the economic growth index, the quantum index of patent application, the trading volume index in the market of technologies and the foreign direct investment index in Shanghai. In the co-integration relationship, the coefficients of quantum index of patent application, trading volume index in the market of technologies are positive values, suggesting that the economic growth is in positive correlation with the advance of science and technol- ogy represented by the quantity of patent application, the sum of business transaction in the market of technologies and foreign direct investment. Under the 95\% confidence level, the coefficient of patent application index is relatively higher, up to 0.42667 . As an important institutional arrangement and the indicator for innovation efforts, patent plays a vital role in the economic development in Shanghai. On the one hand, as the evidence of technical progress, patented inventions innovated and improved the existing technologies, leading to the increase of production rate and the growth in economy; on the other hand, the patent system protects the benefits of inventors as well the social benefit, which can effectively encourage innovation, and promote the social progress and 
economic growth. In the long run, patent, transaction in technology market and foreign direct investment promote and facilitate the development of economy, which is consistent with the previous research achievements.

See from vector auto-regression model, regardless of the influence of variables on themselves, the index of patent output in the current period and the trading volume index in the market of technologies shows a slight impact on the economic growth, which are 1.25 and $6.5 \%$ respectively, while the economic growth index in the current period can pose a significant impact on the quantum index of patent application and trading volume index in the technology market. It suggests that the advance of science and technology in Shanghai such as patent and transaction in technology market still needs a long time to promote the development of economy, and the growth in economy and social progress has a great demand for knowledge, science and technology, and this kind of demand encourages the output of patent and make the transaction in technology market booming. All of the above analysis and conclusion information effectively validates the interactive hypothesis in the interpretation model which has been mentioned earlier.

Based on the analysis on impulse response function in VAR model, it can be seen that: the impact of a standard deviation in the quantity of patent application is positive to the economic growth in the short run, and the influence is not significant after the fourth period, which suggests that the patent output can positively promote the economic growth, and the continuous effectiveness of technology on economy is weak, thus the quality of patent need to be improved. The variation in economic growth can pose a positive disturbance on the patent output and transaction in technology market, and it shows a greater impact on the latter, indicating that the demand for technology by the growth in economy is solved from transaction (namely technology market), and there is no significant relationship between economic growth and foreign direct investment, in other ways, the foreign direct investment in Shanghai is not in the interaction relationship with economic growth.

By means of variance decomposition, it clearly shows the degree of influence among variables. Regardless of the impact of variables on themselves, the contribution rate of transaction in technology market on the variation in economic growth is stable at $40 \%$ in the short run, and the contribution rate of patent output on the economic growth is $10 \%$, while foreign direct investment shows a negligible impact on the growth in economy, which further indicates that the transaction in technology market plays a crucial role in the economic development in Shanghai, and the short-term effect is evident, patent output requires a process to promote the development of economy, but the timeliness of this facilitation needs to be prolonged.

The progress in science and technology has pushed forward the optimal allocation for the factor productivities in the aspects of knowledge, management and technology, resulting in the increase of labour productivities and economic growth as well as social development, at the time when the economy is in growth, the demand for science and technology will be greater, thus a virtuous circle between the advance of science and technology and social development can be taken shape. The result of research in this paper demonstrates that there is a longterm equilibrium relationship between the output of science and technology represented by patent and economic growth, suggesting that the output of science and technology has pushed forward the growth in economy. And foreign direct investment can facilitate the economic growth in Shanghai, while its effect is not significant in the short run. At present, the investment in research and development in Shanghai takes up 2.83\% of GDP, which reaches up to the level of innovation-oriented countries, but as the pioneer in the innovation field around the country, the city of Shanghai need to play a more important role in the scientific and technical innovation, thus it is necessary to increase the research and development investment in Shanghai, and meanwhile energetically attract foreign investment, to improve the quantity and quality of technology spillover and to achieve the sound and rapid development of Shanghai.

\section{Acknowledgements}

Thanks for the financially assistance by National Strategic Promotion Project on Patent (No.: PS2010-010) and Research Project on Humanities and Social Sciences by the Ministry of Education (09YJA820077).

\section{REFERENCES}

[1] P. Romer, "Increasing Returns and Long-Run Growth," Journal of Political Economy, Vol. 94, No. 5, 1986, pp. 1002-1037. doi:10.1086/261420

[2] R. Lucas, "On the Mechanics of Economic Development," Journal of Monetary Economy, Vol. 2, 1988, pp. 3-42. doi:10.1016/0304-3932(88)90168-7

[3] X. K. Yang and J. Boriand, "A Micro-Economic Mechanism for Economic Growth,” Journal of Political Economy, Vol. 99, No. 3, 1991, pp. 460-482. doi:10.1086/261762

[4] R. E. Cave, "Multinational Firm, Competition and Productivity in Host-Country Market,” Economica, Vol. 41, No. 162, 1974, pp. 176-193. doi:10.2307/2553765

[5] M. Blomstorm, "Foreign Direct Invest and Spillover Efficiency in an Underdeveloped Economy: Evidence form the Mexican,” Word Development, Vol. 11, No. 6, 1983, pp. 493-501. doi:10.1016/0305-750X(83)90016-5

[6] G. G. Gachino, “Technological Spillovers from Multina- 
tional Presence towards a Conceptual Framework," Progress in Development Studies, Vol. 10, No. 3, 2010, pp. 193-210. doi:10.1177/146499340901000301

[7] M. Blomström, A. Kokko and M. Zejan, “Optimal Policy in the Presence of Licensed Technology from Abroad," Journal of Political Economy, Vol. 90, No. 5, 1982, pp. 1070-1078. doi:10.1086/261109

[8] C. E. V. Leser, "Measurement of Technical Progress within Scope of a Comprehensive Economic Growth Process-German-Fleck, FH," Journal of the Royal Statistical Society Series A (General), Vol. 130, No. 4, 1967, pp. 558-585. doi:10.2307/2982539

[9] I. M. Kanygin, "Scientific-Technical Potential and LongTerm Economic-Growth," Problems of Economics, Vol. 18, No. 10, 1976, pp. 23-48. doi:10.2753/PET1061-1991181023

[10] B. Q. Ye and X. M. Sun, "Research of Economic Growth Based on Technical Innovation," International Conference on E-Business and E-Government (ICEE), Guang- zhou, 7-9 May 2010, pp. 5227-5230. doi:10.1109/ICEE.2010.1309

[11] A. Greiner, J. Rubart and W. Semmler, "Economic Growth, Skill-Biased Technical Change and Wage Inequality: A Model and Estimations for the US and Europe," Journal of Macroeconomics, Vol. 26, No. 4, 2004, pp. 597-621. doi:10.1016/j.jmacro.2003.05.001

[12] J. Bjorn, "Cities, Systems of Innovation and Economic Development," Innovation-Management Policy \& Practice, Vol. 10, No. 3, 2001, pp. 146-155. doi:10.5172/impp.453.10.2-3.146

[13] C. Brian, "Prospects for Reconciling the Conflict between Economic Growth and Biodiversity Conservation with Technological Progress,” Conservation Biology, Vol. 22, No. 6, 2008, pp. 1389-1398. doi:10.1111/j.1523-1739.2008.01089.x

[14] C. A. Sims, “1980 Macroeconomics and Reality,” Econometrica, Vol. 48, No. 1, 2001, pp. 1-48. doi:10.2307/1912017 